\title{
The effects of exercise and diet program in overweight people - Nordic walking versus walking
}

This article was published in the following Dove Press journal:

Clinical Interventions in Aging

\author{
Valentina Muollo',2 \\ Andrea $\mathrm{P}$ Rossi ${ }^{3}$ \\ Chiara Milanese ${ }^{\prime}$ \\ Elena Masciocchi ${ }^{3}$ \\ Miriam Taylor ${ }^{3}$ \\ Mauro Zamboni ${ }^{3}$ \\ Raffaela Rosa' \\ Federico Schena ${ }^{1,2}$ \\ Barbara Pellegrini ${ }^{1,2}$ \\ 'Department of Neurosciences, \\ Biomedicine, and Movement Sciences, \\ University of Verona, Verona, Italy; \\ ${ }^{2}$ CeRiSM, Sport Mountain and Health \\ Research Centre, University of Verona, \\ Rovereto, Italy; ${ }^{3}$ Department of \\ Medicine, Section of Geriatrics, \\ University of Verona Healthy Aging \\ Center, Verona, Italy
}

Purpose: Nordic walking (NW) has been recommended as a form of exercise for clinical populations. Despite intervention programs designed to face a clinical status may last several months, no longitudinal studies have compared the effect of NW to another usual form of exercise, like walking (W). We evaluated the effects of diet combined with a long-supervised NW versus W training on body composition, aerobic capacity and strength in overweight adults. Patients and methods: Thirty-eight participants, randomized into a NW ( $\mathrm{n}=19,66 \pm 7$ years, body mass index (BMI) 33 \pm 5 )) and a W ( $\mathrm{n}=19,66 \pm 8$ years, BMI $32 \pm 5$ ) group, followed a diet and a supervised training routine 3 times/week for 6 months. The variables assessed at baseline, after 3 and 6 months were: anthropometric indexes (ie, BMI and waist circumference (WC)), body composition, aerobic capacity (oxygen consumption $\left(\mathrm{VO}_{2 \text { peak }}\right)$, peak power output (PPO), 6-min walking test (6MWT)) and strength (maximal voluntary contraction of biceps brachialis $\left(\mathrm{MVC}_{\mathrm{BB}}\right)$ and quadriceps femoris $\left(\mathrm{MVC}_{\mathrm{QF}}\right)$, chair stand and arm curl $(\mathrm{AC})$ ).

Results: After 6 months both NW and W group decreased significantly BMI $(6 \%$ and $4 \%$, respectively) and $\mathrm{WC}(8 \%$ and $4 \%$, respectively), but only the NW group reduced $(P<0.05)$ total body fat $(8 \%)$, android fat $(14 \%)$ and leg fat $(9 \%)$. After 6 months, PPO increased $(P<0.05)$ in both groups, but $\mathrm{VO}_{2 \text { peak }}$ improved $(P<0.05)$ only in the NW group (8\%). After 6 months, 6MWT increased $(P<0.001)$ in both groups and only the NW group improved $(P<0.05)$ in $\mathrm{MVC}_{\mathrm{BB}}(14 \%), \mathrm{MVC}_{\mathrm{QF}}(17 \%)$ and $\mathrm{AC}(35 \%)$.

Conclusion: Our results suggest that NW can give in some relevant health parameters, greater and faster benefits than W. Thus, NW can be a primary tool to counteract the obesity and overweight state in middle-aged adults.

Keywords: longitudinal study, walking with poles, diet, strength, body composition, weight loss

\section{Introduction}

In recent years, the prevalence of overweight and obese adults has dramatically increased in European countries. ${ }^{1}$ Obesity can raise the risk of chronic diseases and early mortality ${ }^{2}$ and lead to disabilities and a reduced quality of life. ${ }^{3}$ In this context, physical exercise plays a crucial role in preventing and counteracting obesity. ${ }^{4,5}$ Given that people with excess weight are not inclined to an active lifestyle, ${ }^{6}$ it is of great importance to promote enjoyable and well-tolerated forms of physical exercise.

Walking is probably the safest form of physical activity, ${ }^{7,8}$ and it can easily be adapted to people with pathological conditions while still providing substantial health benefits. ${ }^{9}$ In the last 20 years, Nordic walking (NW), ie, walking with the dynamic use of specific poles, has become an increasingly popular form of exercise. A correct NW technique recruits the muscles of the upper extremities, ${ }^{10}$ maintains a
Correspondence: Valentina Muollo Department of Neurosciences, Biomedicine, and Movement Sciences, University of Verona, Verona, Italy

Tel +390458425122

$\mathrm{Fax}+390458425131$

Email valentina.muollo@univr.it 
long stride at sustained gait speeds and elicits high exercise demands with low impact forces. ${ }^{11}$ In NW, the movement of the arms raises the heart rate (HR), oxygen consumption $\left(\mathrm{VO}_{2}\right)$ and energy expenditure while keeping the rate of perceived exertion (RPE) lower than would occur while walking at the same speed. ${ }^{10,12-15}$ These characteristics make NW a stimulating form of exercise for overweight or obese persons. ${ }^{16,17}$

Although the acute physiological responses to NW and $\mathrm{W}$ are well documented, ${ }^{12,13,18}$ the studies that investigated the health benefits of NW and W exercise included shorter training periods (ie, 4-12 weeks). ${ }^{19-22}$ However, it would be of great importance to compare the effects of NW and $\mathrm{W}$ throughout longer training periods, particularly in sedentary and clinical populations. ${ }^{23}$ After 12 weeks of training, previous studies ${ }^{20,21}$ found positive effects of NW and $\mathrm{W}$ training on aerobic fitness variables, but the possible benefits on muscle strength are still not clear. ${ }^{19,20,24}$ Moreover, it is also suggested that a deeper investigation, in terms of weight loss with a detailed body composition analysis (eg, obtained with dual-energy X-ray absorptiometry [DXA]) or the combination of a training period with a controlled diet, could better highlight some meaningful differences. ${ }^{24}$

Therefore, the aim of this study was to investigate the effects of a prolonged ( $>12$ weeks) period of supervised NW and W training, combined with a controlled diet, in overweight adults. We expected that NW could lead to greater benefits in cardiopulmonary and aerobic fitness variables, in upper and lower limbs' muscle strength and in anthropometric and body composition indexes.

\section{Materials and methods}

\section{Subjects}

Thirty-eight participants were randomized into NW (6 men and 13 women) and W (5 men and 14 women) groups that took part in a 6-month training and diet program. To randomize the subjects in the two groups, a randomization list with variable width was created of size 4 or 6 . This list was prepared using the STATA/SE 11 software (StataCorp, College Station, Texas, United States). With this software, two randomization lists were created to also stratifying by sex.

The inclusion criteria were sedentary male and female (post-menopausal), aged 50-80, body mass index (BMI) $>27 \mathrm{~kg} / \mathrm{m}^{2}$ and no considerable weight loss (>5\%) in the previous 2 months. The exclusion criteria included cardiovascular diseases and musculoskeletal pathologies. The flow chart of the study is shown in Figure 1.

The study included some data that are part of a larger study (ClinicalTrials.gov number, NCT03212391). The study was approved by the Human Ethics Committee of the University of Verona and was conducted in accordance with the Declaration of Helsinki. The subjects gave their written informed consent.

\section{Training program}

The NW and W groups trained three times per week for 24 weeks under the supervision of an instructed NW coach and an assistant graduate in Sports Sciences. Each participant wore an HR monitor (Polar FT1, Polar, Kempele, Finland) and a pedometer (Geonaute Onwalk 900, Decathlon Group, Villeneuve d'Ascq, France). Each participant received instructions on the correct use of these devices and standardized guidelines on the $\mathrm{Cr}-100$ Borg scale $^{25}$ from the same investigator. During the first month, the NW participants learned the NW technique in accordance to the International NW Federation (INWA) guidelines, whereas the $\mathrm{W}$ group followed the instructions for improving the walking technique.

Each training session lasted between 60 and 90 mins and was divided into three phases: i) warm-up (5 mins), ii) central (40-60 mins) and iii) cool down (10 mins). In the central phase, the participants walked in a natural environment characterized by different pathways that could be covered in maximum of 90 mins. The exercise intensity was prescribed by using the heart rate reserve (HRR), ie, from $40-59 \%$ HRR to $60-84 \% \mathrm{HRR}^{26}$ Each participant knew his own range of HRR (ie, moderate and vigorous) which they had to check frequently while walking. At the end of every session, the coaches registered the number of steps, the mean of HR and RPE achieved by each subject. To be included in the data analysis, each subject had to achieve at least $75 \%$ of the attendance during the 6 months of training sessions.

\section{Dietary intake and hypoenergetic diet}

A trained dietician performed a 7 days dietary recall interview, lasting approximately $40 \mathrm{mins}$, in order to assess the initial dietary habits of each subject enrolled in the study. A recall grid representing 7 days of the prior week and all possible food-encounter times was used. Portion sizes were estimated for foods and fluids by comparing with reference foods and fluids in a booklet of photographs. Daily intake of energy, protein, fat, carbohydrate and 


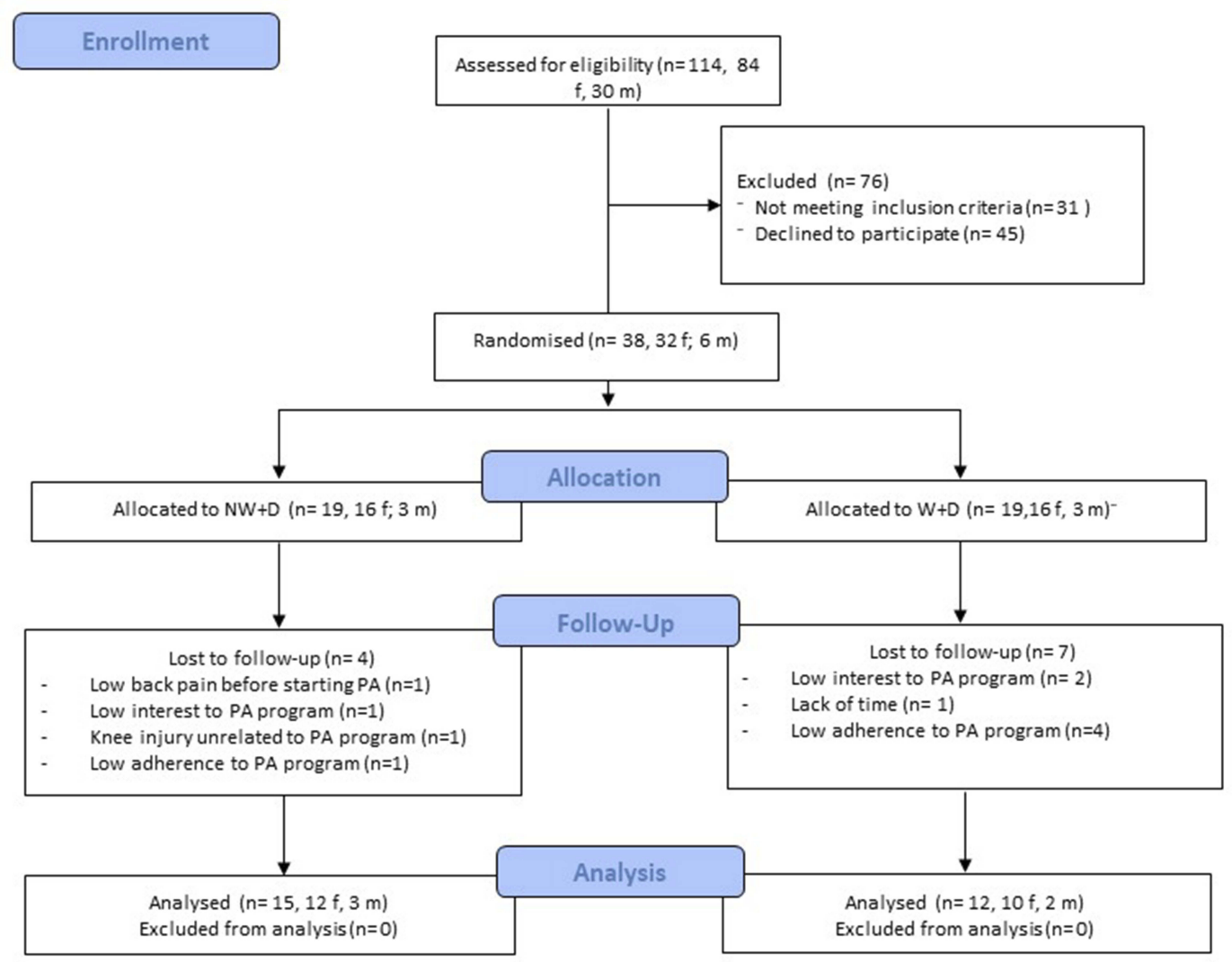

Figure I Flow chart of the study.

Abbreviations: NW, Nordic walking; W, Walking; D, Diet; PA, Physical activity.

alcohol was then calculated based on the tables furnished by the Italian National Institute of Nutrition. ${ }^{27}$

During the study, all the subjects underwent a weightloss program designed to achieve a loss of $5-10 \%$ of the initial weight as previously reported. ${ }^{28}$ The caloric restriction was $500 \mathrm{kcal}$ below the resting energy expenditure, as evaluated by indirect calorimetry and multiplied by a physical activity level of 1.4. Each subject received a diet providing $62 \%$ carbohydrates, $24 \%$ fat, $14 \%$ protein, and $20 \mathrm{~g}$ fiber. The subjects underwent monthly clinical and nutritional follow-ups. Dietary adherence was checked by a $24-\mathrm{h}$ recall every 4 weeks during an outpatient visit.

\section{Anthropometry and body composition measurements}

Waist circumference (WC) was measured at the midpoint between the highest point of the iliac crest and the lowest point of the costal margin in the mid-axillary line. ${ }^{29}$ Total body and regional composition (lean and fat mass) was evaluated by means of DXA, using a total body scanner (QDR Explorer W, Hologic, MA, USA; fan-bean technology, software for
Windows XP version 12.6.1). The android region was taken as the area between the ribs and the pelvis, with an upper demarcation that was $20 \%$ of the distance between the iliac crest and neck and a lower perimeter that coincided with the top of the pelvis. ${ }^{30}$ All scanning and analyses were performed by the same operator to ensure consistency. The estimated precision of whole-body DXA measurements was $2.3 \%$ and $0.5 \%$ for fat and lean mass, respectively.

\section{Aerobic capacity measurements}

An incremental ramp test was performed on a cycloergometer (Excalibur Sport Device, Lode, Netherlands). The protocol consisted of a 1-min rest period, a 3-mins period of warm-up at $20 \mathrm{~W}$ and an increase in power output (PO) of 2 W every $12 \mathrm{~s}$ (ie, $10 \mathrm{~W} / \mathrm{min}$ ) for females and $3 \mathrm{~W}$ every $12 \mathrm{~s}$ (ie, $15 \mathrm{~W} / \mathrm{min}$ ) for males until volitional exhaustion. During the test, gas exchange and minute ventilation $\left(\mathrm{V}_{\mathrm{e}}\right)$ were collected breath by breath using a metabolimeter (Quark PFT, Cosmed, Rome, Italy), HR was monitored through a connected computer, and PO and pedaling frequency were continuously collected by the cycloergometer. Before each 
test, the metabolimeter was calibrated following the manufacturer's instructions. Two expert evaluators determined ventilatory thresholds ${ }^{31}$ by visual inspection. The first ventilatory threshold was identified at the first rapid increase in $\mathrm{V}_{\mathrm{E}}$ followed by an increase in ventilatory equivalent in $\mathrm{VO}_{2}$ $\left(\mathrm{V}_{\mathrm{E}} / \mathrm{VO}_{2}\right)$ and partial pressure of $\mathrm{O}_{2}\left(\mathrm{PO}_{2}\right)$ whereas ventilatory equivalent in $\mathrm{VCO}_{2}\left(\mathrm{~V}_{\mathrm{E}} / \mathrm{VCO}_{2}\right)$ and partial pressure of $\mathrm{CO}_{2}\left(\mathrm{PCO}_{2}\right)$ remained stable. The second ventilatory threshold was identified with the breakpoint where $\mathrm{PCO}_{2}$ began to fall, with an additional increase in $\mathrm{V}_{\mathrm{E}}, \mathrm{V}_{\mathrm{E}} / \mathrm{VO}_{2}$, $\mathrm{V}_{\mathrm{E}} / \mathrm{VCO}_{2}$ and $\mathrm{PO}_{2}$. The POs at the first $\left(\mathrm{PO}_{\mathrm{vt} 1}\right)$ and second $\left(\mathrm{PO}_{\mathrm{vt} 2}\right)$ ventilatory thresholds were calculated.

On a different day, each subject performed the 6-min walking test (6MWT) in a course of 30-m (marked every 5 $\mathrm{m}$ with a tape on the floor) delimited by two training cones. Before starting the 6MWT, the experimenter asked to cover the maximal distance at a self-selected speed for 6 mins. During the test, each participant received verbal encouragement. At the end of the test, the investigator measured the distance covered by the participant.

\section{Strength measurements}

The forces during an isometric maximal voluntary contraction of the brachial biceps $\left(\mathrm{MVC}_{\mathrm{BB}}\right)$ and the quadriceps femoris $\left(\mathrm{MVC}_{\mathrm{QF}}\right)$ were measured through a strain gauge, collected with a sampling frequency of $200 \mathrm{~Hz}$ and recorded on a personal PC using LabChart7. For testing the $\mathrm{MVC}_{\mathrm{BB}}$, the subject was sitting on a chair with the dominant arm flexed at $90^{\circ}$. For testing the $\mathrm{MVC}_{\mathrm{QF}}$, the subject was sitting on the tested chair with a flexion angle of $90^{\circ}$ of the dominant knees, with the ankle fixed by a strap in line with the strain gauge. Before the tests, the experimenter gave the instruction to execute a contraction "as hard as possible," ${ }^{, 32}$ and during the tests, participants were encouraged to deliver the maximal force. After a standardized warm-up and a familiarization trial, the subjects performed six MVCs interspersed by $60 \mathrm{~s}$ of rest. Averaged peak force values of the best three over a total of six contractions provided the $\mathrm{MVC}_{\mathrm{BB}}$ and the $\mathrm{MVC}_{\mathrm{QF}}$.

Arm curl (AC) and chair stand (CS) tests ${ }^{33}$ were used to test muscular endurance. Participants were asked to perform in $30 \mathrm{~s}$ the maximal number of flexion-extension of the dominant elbow with a dumbbell ( 8 or $5 \mathrm{lbs}$ for men and women, respectively) and the maximal number of stand-ups, starting on a seated position with both arms crossed on the chest.

\section{Statistical analysis}

A Student's $t$-test was used to verify any baseline differences between the groups and differences in the training sessions. A two-way (group $\times$ time) repeated measures ANOVA was conducted. In the case of a time $\times$ group interaction, a between-group (ie, NW vs W) ANOVA was also used to assess for changes across time within each group. In the case of statistically significant differences, a pairwise comparison between groups was carried out, adjusting the significance level with Bonferroni correction. To further investigate changes over time in the NW and $\mathrm{W}$ groups separately, a within-group one-way repeated measure ANOVA was run. The assumption of normality and sphericity was ascertained before using parametric tests. SPSS software (IBM SPSS Statistics Version 22, Chicago, IL, USA) was used for the statistical analysis. A level of significance was accepted at $P<0.05$.

\section{Results}

No significant differences between the groups were found for diet (Table S1) and for the parameters at baseline (Tables 1 and 2).

\section{Training characteristics and adherence to the intervention}

At the end of the study, the total dropout was $21 \%$ and $36 \%$ in the NW and W groups, respectively (Figure 1).

The monthly mean values of steps count (Figure S1) increased over time $(P=0.001)$, with no time $\times$ group interaction $(P=0.982)$ and no significant differences between the two groups $(P=0.323)$. The $\mathrm{HR}_{\text {mean }}$ increased $(P<0.001)$, without time $\times$ group interaction $(P=0.370)$ and differ significantly among the two groups $(p=0.015)$; the $\mathrm{HR}_{\text {mean }}$ was significantly higher in NW group in month $1(P=0.008)$, month 2 $(P=0.009)$, month $3(P=0.009)$, month $5(P=0.022)$, month 6 $(P=0.023)$. The RPE values decreased over time $(P<0.001)$, without any time $\times$ group interaction $(P=0.111)$ and differ significantly among the two groups $(P=0.045)$. RPE was significantly lower in the NW compared to $\mathrm{W}$ group at the end of month $1 \quad(P=0.035)$, month $2(P=0.051)$ and month 5 $(P=0.049)$ of training.

The monthly mean values of HR and RPE recorded at the end of the training sessions in the NW and $\mathrm{W}$ groups are presented in Figure 2. 
Table I Characteristics of trial groups, anthropometric and body composition measurements

\begin{tabular}{|c|c|c|c|c|c|}
\hline \multirow[b]{2}{*}{ Measurement } & \multicolumn{3}{|c|}{ Assessment period } & \multicolumn{2}{|l|}{$P$-value } \\
\hline & Baseline & 3 months & 6 months & Baseline & Time within-group \\
\hline \multicolumn{6}{|l|}{ Age } \\
\hline $\begin{array}{l}\text { NW } \\
W\end{array}$ & $\begin{array}{l}66.0 \pm 6.7 \\
65.5 \pm 7.7\end{array}$ & & & 0.859 & \\
\hline \multicolumn{6}{|l|}{ Height (m) } \\
\hline $\begin{array}{l}\text { NW } \\
W\end{array}$ & $\begin{array}{l}1.6 \pm 0.1 \\
1.6 \pm 0.1\end{array}$ & & & 0.514 & \\
\hline \multicolumn{6}{|l|}{ Weight (kg) } \\
\hline $\begin{array}{l}\text { NW } \\
W\end{array}$ & $\begin{array}{l}83.1 \pm 12.4 \\
81.5 \pm 11.5\end{array}$ & $\begin{array}{l}79.0 \pm 12.9^{\mathrm{a}} \\
79.2 \pm 12.4^{\mathrm{a}}\end{array}$ & $\begin{array}{l}78.2 \pm 13.5^{c} \\
78.1 \pm 13.3^{c}\end{array}$ & 0.725 & $\begin{array}{l}0.001 \\
0.002\end{array}$ \\
\hline \multicolumn{6}{|l|}{ BMI $\left(\mathrm{kg} / \mathrm{m}^{2}\right)$} \\
\hline $\begin{array}{l}\text { NW } \\
W\end{array}$ & $\begin{array}{l}33.2 \pm 4.5 \\
32.0 \pm 5.3\end{array}$ & $\begin{array}{l}31.6 \pm 4.7^{\mathrm{a}} \\
31.0 \pm 5.2^{\mathrm{a}}\end{array}$ & $\begin{array}{l}31.2 \pm 4.9^{c} \\
30.6 \pm 5.3^{c}\end{array}$ & 0.514 & $\begin{array}{l}0.001 \\
0.001\end{array}$ \\
\hline \multicolumn{6}{|l|}{ WC (cm) } \\
\hline $\begin{array}{l}\text { NW } \\
W\end{array}$ & $\begin{array}{l}103.4 \pm 10.2 \\
102.4 \pm 10\end{array}$ & $\begin{array}{l}98.8 \pm 8.4^{\mathrm{a}} \\
99.8 \pm 10.5^{\mathrm{a}}\end{array}$ & $\begin{array}{l}97.5 \pm 8.5^{\mathrm{b}, \mathrm{c}} \\
99.1 \pm 10.3^{\mathrm{b}, \mathrm{c}}\end{array}$ & 0.795 & $\begin{array}{l}0.001 \\
0.001\end{array}$ \\
\hline \multicolumn{6}{|l|}{ BF $_{\text {тот }}(\mathbf{k g})$} \\
\hline $\begin{array}{l}\text { NW } \\
W\end{array}$ & $\begin{array}{l}33.5 \pm 7.0 \\
32.7 \pm 7.5\end{array}$ & $\begin{array}{l}30.8 \pm 7.6^{\mathrm{a}} \\
31.5 \pm 7.5\end{array}$ & $\begin{array}{l}30.8 \pm 7.8^{c} \\
30.5 \pm 7.2\end{array}$ & 0.784 & $\begin{array}{l}0.001 \\
0.007\end{array}$ \\
\hline \multicolumn{6}{|l|}{ BL тот (kg) } \\
\hline $\begin{array}{l}\text { NW } \\
\text { W }\end{array}$ & $\begin{array}{l}46.7 \pm 8.6 \\
45.8 \pm 9.2\end{array}$ & $\begin{array}{l}46.2 \pm 8.0 \\
45.6 \pm 8.9\end{array}$ & $\begin{array}{l}45.5 \pm 8.5 \\
45.5 \pm 9.7\end{array}$ & 0.826 & $\begin{array}{l}0.074 \\
0.713\end{array}$ \\
\hline \multicolumn{6}{|l|}{ Arm fat (kg) } \\
\hline $\begin{array}{l}\text { NW } \\
\text { W }\end{array}$ & $\begin{array}{l}2.1 \pm 0.4 \\
2.1 \pm 0.7\end{array}$ & $\begin{array}{l}2.0 \pm 0.5 \\
2.0 \pm 0.7\end{array}$ & $\begin{array}{l}1.9 \pm 0.5 \\
2.0 \pm 0.8\end{array}$ & 0.956 & $\begin{array}{l}0.039 \\
0.573\end{array}$ \\
\hline \multicolumn{6}{|l|}{ Arm lean (kg) } \\
\hline $\begin{array}{l}\text { NW } \\
\text { W }\end{array}$ & $\begin{array}{l}2.3 \pm 0.6 \\
2.0 \pm 0.5\end{array}$ & $\begin{array}{l}2.2 \pm 0.6 \\
2.1 \pm 0.6\end{array}$ & $\begin{array}{l}2.2 \pm 0.6 \\
2.1 \pm 0.7\end{array}$ & 0.406 & $\begin{array}{l}0.313 \\
0.280\end{array}$ \\
\hline \multicolumn{6}{|l|}{ Leg fat (kg) } \\
\hline $\begin{array}{l}\text { NW } \\
\text { W }\end{array}$ & $\begin{array}{l}5.2 \pm 1.4 \\
4.9 \pm 1.3\end{array}$ & $\begin{array}{l}4.7 \pm 1.4^{\mathrm{a}} \\
4.9 \pm 1.4\end{array}$ & $\begin{array}{l}4.7 \pm 1.5^{c} \\
4.6 \pm 1.3^{b}\end{array}$ & 0.610 & $\begin{array}{l}0.001 \\
0.012\end{array}$ \\
\hline \multicolumn{6}{|l|}{ Leg lean (kg) } \\
\hline $\begin{array}{l}\text { NW } \\
\text { W }\end{array}$ & $\begin{array}{l}7.2 \pm 1.5 \\
7.0 \pm 1.7\end{array}$ & $\begin{array}{l}6.9 \pm 1.4 \\
7.1 \pm 1.7\end{array}$ & $\begin{array}{l}6.9 \pm 1.5 \\
7.1 \pm 1.8\end{array}$ & 0.848 & $\begin{array}{l}0.130 \\
0.719\end{array}$ \\
\hline \multicolumn{6}{|l|}{ Trunk fat (kg) } \\
\hline $\begin{array}{l}\text { NW } \\
\text { W }\end{array}$ & $\begin{array}{l}|8 .| \pm 4 . \mid \\
\mid 7.8 \pm 4.3\end{array}$ & $\begin{array}{l}16.6 \pm 4.5 \\
16.8 \pm 4.1\end{array}$ & $\begin{array}{l}16.6 \pm 4.7 \\
16.2 \pm 3.7\end{array}$ & 0.895 & $\begin{array}{l}0.013 \\
0.013\end{array}$ \\
\hline
\end{tabular}


Table I (Continued).

\begin{tabular}{|c|c|c|c|c|c|}
\hline \multirow[b]{2}{*}{ Measurement } & \multicolumn{3}{|c|}{ Assessment period } & \multicolumn{2}{|l|}{$P$-value } \\
\hline & Baseline & 3 months & 6 months & Baseline & Time within-group \\
\hline \multicolumn{6}{|l|}{ Trunk lean (kg) } \\
\hline NW & $24.7 \pm 4.4$ & $25.0 \pm 4.3$ & $24.2 \pm 4.4$ & 0.891 & 0.135 \\
\hline W & $24.5 \pm 4.6$ & $24 . I \pm 4.4$ & $24.0 \pm 4.9$ & & 0.318 \\
\hline \multicolumn{6}{|c|}{ Android fat (kg) } \\
\hline NW & $2.7 \pm 0.8$ & $2.3 \pm 0.9^{\mathrm{a}}$ & $2.3 \pm 0.8^{c}$ & $0.54 I$ & 0.001 \\
\hline W & $2.5 \pm 0.6$ & $2.4 \pm 0.7$ & $2.3 \pm 0.7$ & & 0.029 \\
\hline \multicolumn{6}{|c|}{ Android lean (kg) } \\
\hline NW & $3.3 \pm 0.8$ & $3.3 \pm 0.8$ & $3.3 \pm 0.7$ & 0.839 & 0.610 \\
\hline W & $3.4 \pm 0.8$ & $3.3 \pm 0.8$ & $3.2 \pm 0.1$ & & 0.131 \\
\hline
\end{tabular}

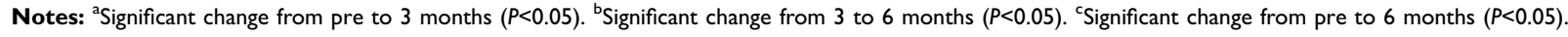

\section{Anthropometry and body composition}

A significant decrease in BMI was seen over time $(P=0.001)$ without any time $\times$ group interaction $(P=0.329)$. After 3 and 6 months of training, BMI significantly reduced in both NW (5\% and $6 \%$, respectively) and $\mathrm{W}$ (3\% and $5 \%$, respectively) group.

WC reduced over time $(P=0.001)$ with a trend in time $\times$ group interaction $(P=0.062)$. After 3 and 6 months, WC significantly decreased in both NW $(9 \%$ and $5 \%$, respectively) and $\mathrm{W}$ ( $3 \%$ and $4 \%$, respectively) group.

$\mathrm{BF}_{\mathrm{TOT}}$, trunk fat and android fat reduced over time $(P=0.001)$ without any time $\times$ group interaction $(P=0.301$; $P=0.712 ; P=0.162$, respectively). For the within-group analysis, after 3 and 6 months of training, only the NW group showed a significant reduction in $\mathrm{BF}_{\mathrm{TOT}}(8 \%)$ and android fat (13\% and $14 \%$, respectively). For leg fat, there was a significant decrease over time $(P=0.001)$ and a time $\times$ group interaction $(P=0.022)$. After 3 months of training, a significant reduction was shown only in the NW group $(9 \%)$ with no differences between the two groups $(P=0.776)$. At the end of the intervention, both NW and W group reduced significantly leg fat ( $9 \%$ and $5 \%$, respectively). The main changes in total and compartmental body fat are summarized in Figure 3.

No significant differences $(P>0.05)$ were found in the two groups for $\mathrm{BL}_{\mathrm{TOT}}$, arm fat, arm lean mass, trunk and android lean mass and leg lean mass (Table 1).

\section{Aerobic capacity}

$\mathrm{VO}_{2 \text { peak }}$ and peak power output (PPO) increased over time ( $P=0.009$ and $P=0.001$, respectively) with no time $\times$ group interaction $(P=0.382$ and $P=0.752$, respectively). After 6 months, the $\mathrm{VO}_{2 \text { peak }}$ increased significantly in the NW group (8\%), while the $\mathrm{W}$ group had no significant changes $(3 \%, P>0.05)$. After 3 and 6 months of training, the PPO increased significantly in both NW $(6 \%$ and $12 \%$, respectively) and $\mathrm{W}$ (7\% and 10\%, respectively) group.

$\mathrm{PO}_{\mathrm{VT} 1}$ and $\mathrm{PO}_{\mathrm{VT} 2}$ improved over time $(P=0.001)$ with no time $\times$ group interaction $(P=0.653 ; P=0.707$, respectively). After 3 and 6 months, $\mathrm{PO}_{\mathrm{VT} 1}$ increased significantly in NW (13\% and 19\%, respectively) and $\mathrm{W}$ (7\% and $19 \%$, respectively) group. Moreover, $\mathrm{PO}_{\mathrm{VT} 2}$ increased in both NW (7\% and 13\%, respectively) and W (9\% and $16 \%$, respectively) group.

There was a significant increase in 6MWT over time $(P=0.001)$ with a time $\times$ group interaction $(P=0.050)$. After 3 months, only the NW group improved significantly 6MWT (7\%), but no differences were observed between the two groups $(P=0.347)$. At the end of the intervention, the 6MWT improved significantly in both NW (13\%) and $\mathrm{W}(9 \%)$ group.

\section{Muscular strength}

$\mathrm{MVC}_{\mathrm{BB}}$ and $\mathrm{MVC}_{\mathrm{QF}}$ increased over time $(P=0.001)$ with no time $\times$ group interaction $(P=0.501 ; P=0.148$, respectively). The within-group analysis revealed that after 3 and 6 months, only the NW group improved significantly $\mathrm{MVC}_{\mathrm{BB}}\left(9 \%\right.$ and $14 \%$, respectively) and $\mathrm{MVC}_{\mathrm{QF}}(23 \%$ and $17 \%$, respectively).

There was an increase in $\mathrm{AC}$ over time $(P=0.002)$ and a time $\times$ group interaction $(P=0.013)$. After 6 months, only the NW group improved significantly AC (35\%); however, 
Table 2 Aerobic and strength measurements

\begin{tabular}{|c|c|c|c|c|c|}
\hline \multirow[b]{2}{*}{ Measurement } & \multicolumn{3}{|c|}{ Assessment period } & \multicolumn{2}{|l|}{$P$-value } \\
\hline & Baseline & 3 months & 6 months & Baseline & Time within-group \\
\hline \multicolumn{6}{|l|}{ PPO (w) } \\
\hline NW & $131.0 \pm 40.0$ & $139 \pm 41.5^{\mathrm{a}}$ & $|45.7 \pm 4| .6^{\mathrm{b}, \mathrm{c}}$ & 0.779 & 0.001 \\
\hline W & $126.0 \pm 35.7$ & $134.3 \pm 36.8^{\mathrm{a}}$ & $138.5 \pm 33.2^{c}$ & & 0.001 \\
\hline \multicolumn{6}{|c|}{$\mathrm{VO}_{2 \text { peak }}(\mathrm{mL} / \mathrm{min} / \mathrm{kg})$} \\
\hline NW & $22.9 \pm 4.7$ & $24.7 \pm 4.7$ & $25.1 \pm 4.7^{c}$ & 0.581 & 0.007 \\
\hline W & $22.3 \pm 4.3$ & $23.1 \pm 3.8$ & $23.0 \pm 2.5$ & & 0.434 \\
\hline \multicolumn{6}{|l|}{ PO $_{v t l}(w)$} \\
\hline NW & $64.8 \pm 19.3$ & $73.0 \pm 18.4^{\mathrm{a}}$ & $77.0 \pm 20.6^{\mathrm{b}, \mathrm{c}}$ & 0.924 & 0.001 \\
\hline W & $68.0 \pm 17.4$ & $72.7 \pm 17.4^{\mathrm{a}}$ & $80.6 \pm 13.6^{c}$ & & 0.002 \\
\hline \multicolumn{6}{|l|}{$\mathbf{P O}_{\mathrm{vt2}}(\mathrm{w})$} \\
\hline NW & $98.7 \pm 29.4$ & $105.9 \pm 29.1^{\mathrm{a}}$ & $111.9 \pm 29.6^{\mathrm{b}, \mathrm{c}}$ & 0.821 & 0.001 \\
\hline W & $98.4 \pm 25.7$ & $107.7 \pm 29.1^{\mathrm{a}}$ & $114.3 \pm 22.2^{c}$ & & 0.002 \\
\hline \multicolumn{6}{|l|}{ 6MWT (m) } \\
\hline NW & $555.4 \pm 73.4$ & $592.4 \pm 62.9^{\mathrm{a}}$ & $625.5 \pm 57.2^{\mathrm{b}, \mathrm{c}}$ & 0.901 & 0.001 \\
\hline W & $558.8 \pm 62.9$ & $570.4 \pm 54.1$ & $606.9 \pm 44.2^{\mathrm{b}, \mathrm{c}}$ & & 0.001 \\
\hline \multicolumn{6}{|l|}{$\operatorname{MVC}_{\mathrm{BB}}(\mathrm{N})$} \\
\hline NW & $176.8 \pm 48.0$ & $193.2 \pm 50.4^{\mathrm{a}}$ & $201.1 \pm 52.2^{c}$ & 0.792 & 0.001 \\
\hline W & $167.8 \pm 84.0$ & $177.8 \pm 68.0$ & $181.9 \pm 73.8$ & & 0.233 \\
\hline \multicolumn{6}{|l|}{$\mathrm{MVC}_{\mathrm{QF}}(\mathrm{N})$} \\
\hline NW & $210.1 \pm 105.8$ & $258.1 \pm 50.5^{\mathrm{a}}$ & $254.1 \pm 98.3^{c}$ & 0.334 & 0.001 \\
\hline W & $|77| \pm 88.2$. & $195.4 \pm 92.7$ & $196.7 \pm 10 \mid .6$ & & 0.185 \\
\hline \multicolumn{6}{|l|}{ Arm curl (n) } \\
\hline NW & $18.8 \pm 1.0$ & $22.5 \pm 4.3$ & $25.3 \pm 4.3^{c}$ & 0.971 & 0.004 \\
\hline w & $20.3 \pm 3.8$ & $20.8 \pm 4.4$ & $21.0 \pm 4.3$ & & 0.794 \\
\hline \multicolumn{6}{|l|}{ Chair stand (n) } \\
\hline NW & $15.7 \pm 3.8$ & $20.2 \pm 3.8^{\mathrm{a}}$ & $19.0 \pm 2.3$ & 0.973 & 0.004 \\
\hline w & $15.5 \pm 3.2$ & $21.2 \pm 6.3^{\mathrm{a}}$ & $18.0 \pm 7.1$ & & 0.010 \\
\hline
\end{tabular}

Notes: ${ }^{a}$ Significant change from pre to 3 months $(P<0.05)$. ${ }^{b}$ Significant change from 3 to 6 months $(P<0.05)$. ${ }^{c}$ Significant change from pre to 6 months $(P<0.05)$.

no significant differences were found between the two groups $(P=0.114)$. CS significantly increased over time $(P=0.001)$ with no time $\times$ group interaction $(P=0.539)$. After 3 months, a significant improvement in CS was found in both NW (29\%) and W (37\%) group. However, at the end of the intervention, no significant differences were observed in both groups $(P>0.05)$.

\section{Discussion}

This study investigated the effects of a long period of NW plus diet compared with W plus diet, as well as analyzed cardiorespiratory changes and other aspects of health-related parameters (ie, body composition and muscular strength) in an overweight and obese population.

After 6 months of training, the dropout rate of the participants $(21 \%$ and $36 \%$ in the NW and $\mathrm{W}$ groups, respectively) was higher when compared with rates reported by other studies. ${ }^{34,35}$ The main reasons for this low compliance were the "lack of time" (as declared by the participants) and injuries not related to the exercise program. However, the participants that concluded the training period attended more 

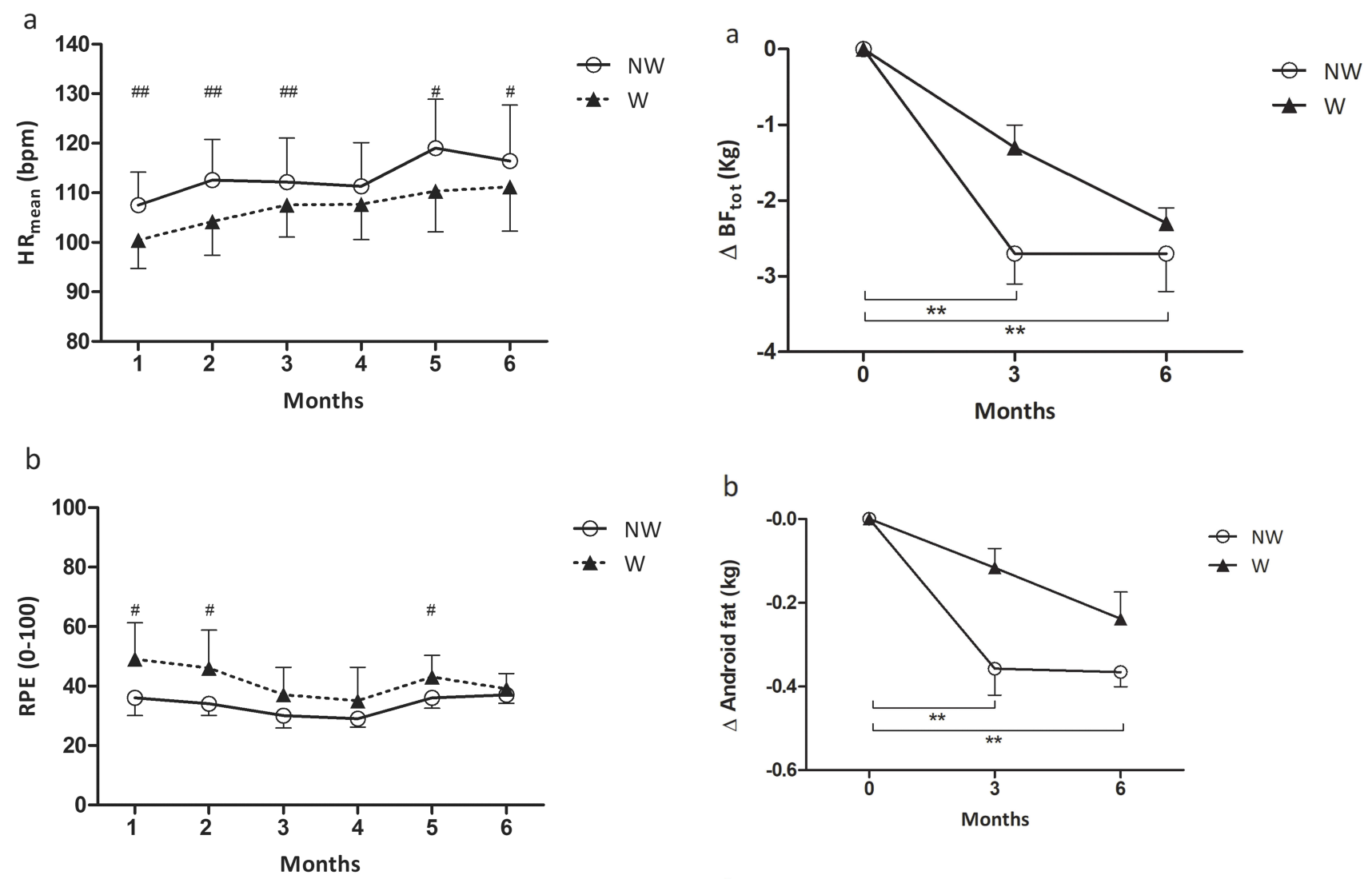

Figure 2 Monthly trend of the heart rate $\left(H R_{\text {mean }}\right.$, panel a) and RPE (panel b) during training sessions in $N W$ and $W$ groups. ${ }^{\#} P<0.05,{ }^{\#} P<0.01$, significant differences between $N W$ and $W$ groups.

Abbreviations: NW, Nordic walking; W, walking; RPE, rate of perceived exertion.

than $80 \%$ of the training sessions. This is in keeping with results available in the literature..$^{20,23}$

In our study, we observed a significant reduction in BMI and $\mathrm{WC}$ in both groups after 3 months, with a further reduction after 6 months, in accordance to other studies. ${ }^{21,34,36}$ However, we reported higher variations in BMI and WC indexes, and this might be because of the controlled diet, which is relevant for enhancing the chances of losing weight. ${ }^{4}$ Regarding the results of body composition, the statistical analysis did not find any significant differences between the two training modalities; however, over time only the NW group had a significant reduction in $\mathrm{BF}_{\text {TOT }}(8 \%)$, with a preferential loss in leg and android fat mass ( $9 \%$ and $14 \%$, respectively). A possible explanation might be that the continuous emphasized movement of the shoulders and trunk in NW helps to mobilize and utilize fatty acid reserves with a positive effect on android fat. ${ }^{37}$

The gain in $\mathrm{VO}_{2 \text { peak }}(8 \%$ for $\mathrm{NW})$ at the end of the intervention was smaller than that reported by others, eg, $+10 \%$ in both NW and $\mathrm{W}$ groups after 13 weeks of training, ${ }^{34}$ $+20 \%$ and $+14 \%$ in the NW and $\mathrm{W}$ groups, respectively, after

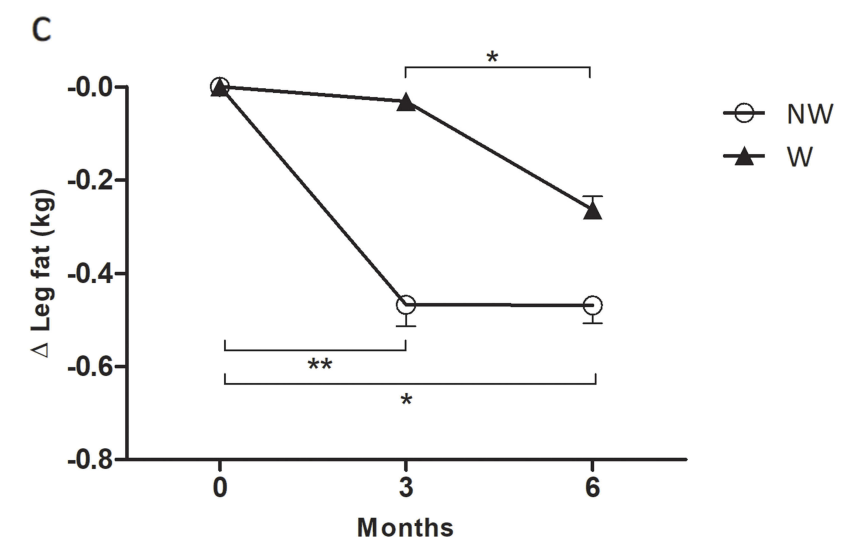

Figure 3 Changes in total body fat $\left(\mathrm{BF}_{\mathrm{TO}}\right.$, panel a), android fat (panel $\mathrm{b}$ ) and leg fat (panel c) in NW and W groups after 3 and 6 months of training. $* P<0.05, * * P<0.01$, significant differences from baseline and from 3 to 6 months.

Abbreviations: NW, Nordic walking; W, walking.

3 weeks. ${ }^{19}$ The differences might be explained by the different protocols used for the incremental test (cycle ergometer in our study vs treadmill). ${ }^{19,34}$ Although walking on a treadmill is a more ecological test, we decided to use a cycling incremental test to focus on the improvements in the aerobic capacity while excluding any possible interference due to the habituation with walking pattern of motion. The increase in PPO in both groups, with a significant improvement on $\mathrm{VO}_{2 \text { peak }}$ only in NW, can be the result of an enhanced capacity to tolerate fatigue. ${ }^{38}$ Regarding the improvements in power at 
submaximal intensity $\left(\mathrm{PO}_{\mathrm{VT} 1}\right.$ and $\left.\mathrm{PO}_{\mathrm{VT} 2}\right)$, we suggest that both forms of training can give enhancements in these exercise capacity parameters over a long period of time. However, the recruitment of the upper muscles in NW can raise the intensity of the stimulus during training sessions. NW group showed a higher $\mathrm{HR}_{\text {mean }}$ with a lower RPE compared with $\mathrm{W}$, in line with other studies ${ }^{10,12,21}$ that can accelerate the physiological adaptations at submaximal intensities.

After 3 months, only the NW group improved in 6MWT, whereas the $\mathrm{W}$ group showed an improvement only after 6 months. Other studies ${ }^{19,20}$ reported an increase in $6 \mathrm{MWT}$ in both groups after 3 months of training. We speculate that the faster changes in the NW group might be due to the aerobic improvements and to the improved capacity in keeping a longer step length at higher locomotion speeds. ${ }^{39,40}$

Although the results did not show significant differences among the two groups in terms of strength, only the NW improved maximal arm and leg strength compared with no significant changes in the $\mathrm{W}$ group. To our knowledge, only the study conducted by Ossowski et al (2016) investigated the effects in maximal leg strength after a period of NW training. Even though NW is mainly an aerobic exercise that can hardly lead to a gain in muscle strength, the process of learning the NW technique could be a stimulus for the neuromuscular component. Indeed, it has been reported that learning a new motor task may increase motor unit recruitment, making these more efficient. ${ }^{41}$ The increase in motor unit recruitment augments the maximal force production, explaining in part the improvements in MVC of the upper and lower limbs without changes in muscle mass. ${ }^{40}$

After 6 months, we observed an increase in AC (35\%) in the NW compared with the $\mathrm{W}$ group, in keeping with previous studies. ${ }^{19,20,22}$ This may reinforce the idea that the use of poles can lead to a higher activation of the upper limb muscles compared with $\mathrm{W},{ }^{10}$ with positive effects on the arm resistance strength. Conversely, the significant effects on lower limbs resistance strength observed after 3 months of training (ie, $29 \%$ and $37 \%$ in NW and $\mathrm{W}$, respectively) degraded in the last 3 months.

\section{Conclusion}

Our study showed that both forms of exercise may be welltolerated for long-supervised training periods in overweight and obese adults. This is of relevance because in interventional studies in clinical populations, the main difficulty is to maintain a high level of adherence, even if the exercise program is supervised. However, the results revealed that when exercise program is associated to a diet, NW program may give additional benefits compared with diet plus $\mathrm{W}$ program in some key health-related parameters: 1) can be a suitable tool for patients with excess abdominal fat, therefore reducing the cardiovascular risks factors; 2) can increase the intensity of exercise with a tolerated fatigue, encouraging subjects with a low level of physical fitness to maintain the minimal dose of exercise recommended; 3) can increase muscle strength, while preserving muscle mass and counteracting the detrimental effects of aging/obese state on the maximal isometric strength; 4) can lead to faster changes in some exercise-related parameters.

Interventional studies where a specific comparison between NW and W is protracted and an unsupervised intervention is included should be encouraged. Particularly, studies investigating the effects on strength and compartmental fat with a greater sample of obese patients would be highly relevant for increasing the efficacy of interventions for overweight individuals.

\section{Data sharing statement}

The individual de-identified participant data will not be shared by the authors following the publication.

\section{Acknowledgments}

The study was supported by the Azienda Ospedaliera Universitaria di Verona (Grant number NCT03212391). The authors thank the subjects who voluntarily participated in the study and thank Cantor Tarperi for the valuable technical assistance during data collection.

\section{Disclosure}

The authors have no conflicts of interests to declare in this work.

\section{References}

1. Gallus S, Lugo A, Murisic B, Bosetti C, Boffetta P, La Vecchia C. Overweight and obesity in 16 European countries. Eur J Nutr. 2015;54 (5):679-689. doi:10.1007/s00394-014-0746-4

2. Abdelaal M, Le Roux CW, Docherty NG. Morbidity and mortality associated with obesity. Ann Transl Med. 2017;5(7). doi:10.21037/ atm.2017.03.107

3. Taylor VH, Forhan M, Vigod SN, Mcintyre RS, Morrison KM. The impact of obesity on quality of life. Best Pract Res Clin Endocrinol Metab. 2013;27:139-146. doi:10.1016/j.beem.2013.04.004

4. Swift DL, Johannsen NM, Lavie CJ, Earnest CP, Church TS. The role of exercise and physical activity in weight loss and maintenance. Prog Cardiovasc Dis. 2014;56(4):441-447. doi:10.1016/j.pcad.2013.09.012

5. Donnelly JE, Blair SN, Jakicic JM, Manore MM, Rankin JW, Smith BK. Appropriate physical activity intervention strategies for weight loss and prevention of weight regain for adults. Med Sci Sports Exer. 2009;41(2):459-471. doi:10.1249/MSS.0b013e3181949333 
6. Roda C, Charreire H, Feuillet T, et al. Lifestyle correlates of overweight in adults: a hierarchical approach (the SPOTLIGHT project). Int J Behav Nutr Phys Act. 2016;13:114. doi:10.1186/s12966-0160439-x

7. Kassavou A, Turner A, French DP. Do interventions to promote walking in groups increase physical activity? A meta-analysis. Int $J$ Behav Nutr Phys Act. 2013;10(1):18. doi:10.1186/1479-5868-10-105

8. Meads C, Exley J. A systematic review of group walking in physically healthy people to promote physical activity. Int $J$ Technol Assess Health Care. 2018;34(1):27-37. doi:10.1017/S0266462317001088

9. Lee IM, Buchner DM. The importance of walking to public health. Med Sci Sports Exerc. 2008;40(7 Suppl):S512-S518. doi:10.1249/ MSS.0b013e31817c65d0

10. Pellegrini B, Peyré-Tartaruga LA, Zoppirolli C, et al. Exploring muscle activation during nordic walking: a comparison between conventional and uphill walking. PLoS One. 2015;10(9):e0138906. doi:10.1371/journal.pone. 0138906

11. Park SK, Yang DJ, Kang YH, Kim JH, Uhm YH, Lee YS. Effects of Nordic walking and walking on spatiotemporal gait parameters and ground reaction force. J Phys Ther Sci. 2015;27(9):2891-2893. doi: $10.1589 /$ jpts.27.2891

12. Figard-Fabre H, Fabre N, Leonardi A, Schena F. Physiological and perceptual responses to Nordic walking in obese middle-aged women in comparison with the normal walk. Eur J Appl Physiol. 2010;108 (6):1141-1151. doi:10.1007/s00421-009-1315-z

13. Schiffer T, Knicker A, Montanarella M, Strüder HK. Mechanical and physiological effects of varying pole weights during Nordic walking compared to walking. Eur J Appl Physiol. 2011;111(6):1121-1126. doi:10.1007/s00421-010-1739-5

14. Cebula A, Tyka AK, Pilch W, et al. Effects of 6-week Nordic walking training on body composition and antioxidant status for women $>55$ years of age. Int J Occup Med Environ Health. 2017;30(3):445-454. doi:10.13075/ijomeh.1896.00860

15. Pilch W, Tota $Ł$, Piotrowska A, et al. Effects of nordic walking on oxidant and antioxidant status: levels of calcidiol and proinflammatory cytokines in middle-aged women. Oxid Med Cell Longev. 2018;2018:1-6. doi:10.1155/2018/6468234

16. Tschentscher M, Niederseer D, Niebauer J. Health benefits of Nordic walking: a systematic review. Am J Prev Med. 2013;44(1):76-84. doi:10.1016/j.amepre.2012.09.043

17. Skórkowska-Telichowska K, Kropielnicka K, Bulińska K, et al. Nordic walking in the second half of life. Aging Clin Exp Res. 2016;28(6):1035-1046. doi:10.1007/s40520-016-0531-8

18. Pellegrini B, Boccia G, Zoppirolli C, et al. Muscular and metabolic responses to different Nordic walking techniques, when style matters. Di Giminiani R, ed. PLoS One. 2018;13(4):e0195438. doi:10.1371/ journal.pone. 0195438

19. Kocur P, Deskur-Śmielecka E, Wilk M, Dylewicz P. Effects of Nordic Walking training on exercise capacity and fitness in men participating in early, short-term inpatient cardiac rehabilitation after an acute coronary syndrome - a controlled trial. Clin Rehabil. 2009;23 (11):995-1004. doi:10.1177/0269215509337464

20. Takeshima N, Islam MM, Rogers ME, et al. Effects of Nordic walking compared to conventional walking and band-based resistance exercise on fitness in older adults. J Sports Sci Med. 2013;12 (3):422-430.

21. Figard-Fabre H, Fabre N, Leonardi A, Schena F. Efficacy of nordic walking in obesity management. Int J Sports Med. 2011;32(06):407414. doi: $10.1055 / \mathrm{s}-0030-1268461$

22. Parkatti T, Perttunen J, Wacker P. Improvements in functional capacity from Nordic walking: a randomized controlled trial among older adults. J Aging Phys Act. 2012;20(1):93-105.

23. Fritschi JO, Brown WJ, Laukkanen R, van Uffelen JGZ. The effects of pole walking on health in adults: a systematic review. Scand J Med Sci Sports. 2012;22(5):70-78. doi:10.1111/j.1600-0838.2012.01495.x
24. Bullo V, Gobbo S, Vendramin B, et al. Nordic walking can be incorporated in the exercise prescription to increase aerobic capacity, strength, and quality of life for elderly: a systematic review and metaanalysis. Rejuvenation Res. 2018;21(2):141-161. doi:10.1089/ rej.2017.1921

25. Borg E, Borg G. A comparison of AME and CR100 for scaling perceived exertion. Acta Psychol (Amst). 2002;109(2):157-175. doi:10.1016/S0001-6918(01)00055-5

26. Riebe D, Franklin BA, Thompson PD, et al. Updating ACSM_s recommendations for exercise preparticipation health screening. Med Sci Sports Exerc. 2015;47(8):2473-2479. doi:10.1249/ MSS.0000000000000664

27. Carnovale E, Marletta L. Tabelle Di Composizione Degli Alimenti: Edizione 1997. Roma: Istituto nazionale della nutrizione; 1997.

28. Rossi AP, Fantin F, Zamboni GA, et al. Effect of moderate weight loss on hepatic, pancreatic and visceral lipids in obese subjects. Nutr Diabetes. 2012;2:32. doi:10.1038/nutd.2012.5

29. Wing RR, Jakicic J, Neiberg R, et al. Risk factors in type 2 diabetes: look AHEAD study. Med Sci Sports Exerc. 2007;39(12):2107-2116. doi:10.1249/mss.0b013e31815614cb

30. Kang SM, Yoon JW, Ahn HY, et al. Android fat depot is more closely associated with metabolic syndrome than abdominal visceral fat in elderly people. Fadini GP, ed. PLoS One. 2011;6(11):e27694. doi:10.1371/journal.pone.0027694

31. Rossiter HB. Exercise: kinetic considerations for gas exchange. ComprPhysiol. 2010;1(1):203-244. doi:10.1002/cphy.c090010

32. Maffiuletti NA, Aagaard P, Blazevich AJ, Folland J, Tillin N, Duchateau J. Rate of force development: physiological and methodological considerations. Eur J Appl Physiol. 2016;116(6):10911116. doi:10.1007/s00421-016-3346-6

33. Rikli RE, Jones CJ. Development and validation of a functional fitness test for community-residing older adults. J Aging Phys Act. 1999;7(2):129-161. doi:10.1123/japa.7.2.129

34. Kukkonen-Harjula K, Hiilloskorpi H, Mänttäri A, et al. Self-guided brisk walking training with or without poles: a randomized-controlled trial in middle-aged women. Scand J Med Sci Sports. 2007;17 (4):316-323. doi:10.1111/j.1600-0838.2006.00585.x

35. Collins EG, Langbein WE, Orebaugh C, et al. Cardiovascular training effect associated with polestriding exercise in patients with peripheral arterial disease. J Cardiovasc Nurs. 2005;20(3):177-185.

36. Song M-S, Yoo Y-K, Choi C-H, Kim N-C. Effects of nordic walking on body composition, muscle strength, and lipid profile in elderly women. Asian Nurs Res (Korean Soc Nurs Sci). 2013;7(1):1-7. doi:10.1016/j.anr.2012.11.001

37. Lee JJ, Pedley A, Hoffmann U, Massaro JM, Fox CS. Association of changes in abdominal fat quantity and quality with incident cardiovascular disease risk factors. J Am Coll Cardiol. 2016;68(14):15091521. doi:10.1016/j.jacc.2016.06.067

38. Castro EA, Peinado AB, Benito PJ, Galindo M, González-Gross M, Cupeiro R. What is the most effective exercise protocol to improve cardiovascular fitness in overweight and obese subjects? J Sport Health Sci. 2017;6(4):454-461. doi:10.1016/j.jshs.2016.04.007

39. Figueiredo S, Finch L, Mai J, Ahmed S, Huang A, Mayo NE. Nordic walking for geriatric rehabilitation: a randomized pilot trial. Disabil Rehabil. 2013;35(12):968-975. doi:10.3109/ 09638288.2012.717580

40. Ossowski ZM, Skrobot W, Aschenbrenner P, Cesnaitiene VJ, Smaruj M. Clinical Interventions in Aging Dovepress effects of short-term nordic walking training on sarcopenia-related parameters in women with low bone mass: a preliminary study. Clin Interv Aging. 2016;111763. doi:10.2147/CIA.S118995

41. Shigemori K, Nagino K, Nakamata E, et al. Motor learning in the community-dwelling elderly during nordic backward walking. $J$ Phys Ther Sci. 2014;26(5):741-743. doi:10.1589/jpts.26.741 


\section{Publish your work in this journal}

Clinical Interventions in Aging is an international, peer-reviewed journal focusing on evidence-based reports on the value or lack thereof of treatments intended to prevent or delay the onset of maladaptive correlates of aging in human beings. This journal is indexed on PubMed Central, MedLine, CAS, Scopus and the Elsevier
Bibliographic databases. The manuscript management system is completely online and includes a very quick and fair peer-review system, which is all easy to use. Visit http://www.dovepress.com/ testimonials.php to read real quotes from published authors.

Submit your manuscript here: https://www.dovepress.com/clinical-interventions-in-aging-journa 